\title{
Overview of Intelligent Tutoring System in Human Teamwork and Its Impact Generally on Learning
}

\author{
Chidi Ukamaka Betrand ${ }^{1, *}$, Sylvanus Okwudili Anigbogu ${ }^{2}$, Stanley Adiele Okolie $^{1}$ \\ ${ }^{1}$ Department of Computer Science, Federal University of Technology, Owerri, Nigeria \\ ${ }^{2}$ Department of Computer Science, Nnamdi Azikiwe University, Awka, Nigeria
}

Email address:

chidi.betrand@futo.edu.ng (C. U. Betrand)

${ }^{*}$ Corresponding author

\section{To cite this article:}

Chidi Ukamaka Betrand, Sylvanus Okwudili Anigbogu, Stanley Adiele Okolie. Overview of Intelligent Tutoring System in Human Teamwork and Its Impact Generally on Learning. International Journal of Intelligent Information Systems. Vol. 10, No. 1, 2021, pp. 5-8. doi: $10.11648 /$ j.ijiis.20211001.12

Received: March 13, 2021; Accepted: March 30, 2021; Published: April 29, 2021

\begin{abstract}
Teams can be depicted in many organizations and is becoming increasingly used for effective and efficient productivity. Teams work as the collection of individuals that have different skills to complement each other rather than compete, their driving force is to achieve a common goal by inculcating strategical approaches of which they are held accountable. This, helps in maximizing general output, however the need of its incorporation in learning. This study presents an overview of Intelligent Tutoring System and its impact generally on learning. A review of previous works done on this area was also inculcated in this study highlighting their importance and relevance. Intelligent Tutoring System (ITS), been a machine intelligence learning paradigm. This research explores and unveils what an intelligent tutoring system is all about and its role in learning. The work also covers how intelligent tutoring system has enhanced learner's skill and performance. In conclusion, the massive effects of intelligent tutoring system on the learning process are acknowledged.
\end{abstract}

Keywords: Intelligent Tutoring System, Human Teamwork, Team, Impact, Learning

\section{Introduction}

Teams allow the distribution of workloads among individuals with different expertise, and improved team performance is prompted by effective teamwork. Statistics has shown that about $82 \%$ of companies are making use of massive team structures [1]. The use of teams leading to maximum organizational outputs in the different sectors [2]. The same scenario is playing out in different countries of the world where teams instead of jobs have become the major building block of organizations [3]. The same is believed to be so all over the different continents of the world. Teams allow the distribution of workloads among individuals with different expertise, and improved team performance is prompted by effective teamwork. Some form of teamwork had taken place since the inception of mankind, and there are three aspects of team definition that are very important.

Teamwork depicts the totality of interaction among individuals, group efforts and also interdependency among the team members. This resultant effect of teamwork is the joint effort in a supportive environment to achieve set down goals through sharing of knowledge and skills. All members contribute to distribute best practices and maximum output.

The notion of a common goal is what actually differentiates a team from other working groups with certain degree of interaction and exchange of resources.

Another unique feature of a team is that some kind of organizational structures are imposed on the team members and also there is an existence of dependency in carrying out tasks to enhance shared resources.

Intelligent tutoring System has been used over the years for effective management of teams to enhance teamwork's skills development for maximizing productivity.

\section{Brief Literature Review on Intelligent Tutoring System}

Intelligent Tutoring System (ITS) are the earliest 
application of Artificial Intelligence learning. ITS employs the techniques from Artificial Intelligence in providing feedback that help learning.Various works on ITS has been implemented, each with its own methodology and mode of operation.

An Intelligent Tutoring System to help students learn C\# programming language efficiently and make the learning procedure very pleasing was developed. The System made use of a knowledge base using ITSB authoring tool style to represent students work and also give customized feedback and support to the students [4].

A desktop based intelligent tutoring system for teaching diabetes was designed and developed using clinical medicine books, doctors and questionnaires. The system helped the students to deeply understand diabetes, its types and diagnoses. It also provides immediate and customized feedback [5].

Intelligent Tutoring System for teaching oracle [6] was designed to support students in oracle Programming. The system was developed using ITSB authoring tool. The system presents the topic of introduction to oracle with automatically generated problems for student to solve.

An Intelligent Tutoring System that help trainees overcome difficulties they face while working in ARDUINO platform was presented. The authoring tool intelligent tutoring system builder was used to design and develop the system. The tool as any normal ITS has four modules: the user interface module, the pedagogical module, the student module and the domains module [7].

A conference paper on Intelligent Coaching Space was presented demonstrating an immersive virtual environment in which the users learn a motor right under a virtual coach supervision. The trainee was led through a coaching session. The system combined expertise from several disciplines such as sport, psychology, computer graphics, human computer interaction and computational linguistics. It demonstrated a short coaching interaction where the user is taught to do a perfect squat [8].

TARDIS, an intelligent virtual coaching agent used in job interviews was presented. The study aimed to build a scenario based game simulation framework that support training in the job interviews context. Youngsters can explore, practice and improve their social skills in a diverse range of possible interview situations. They interact with virtual agents, which are designed to deliver realistic socioemotional interaction and act as recruiters. It actually constituted a common approach to helping people in acquiring and improving their social competencies, especially in the context of job interviews [9].

An agent based framework for simulating engineering teamwork using JADE, was designed. It is an agent-based software framework written in Java [10].

An agent -based personalized e- learning environment to reduce the effort required for learning a course. The system comprises of the Learner Agent that fetches different information according to the different user's demands. The Teacher's Agent which offers help to operation in proper time whenever users call for help and then the Systems
Agent. A system website providing personalized course learning was developed, Java technology was used for the isomerism of the platform [11].

A real time multimodal feedback system for cardiopulmonary resuscitation training, CPR tutor [12] was designed to diagnose mistakes using recurrent neural network. The system also provides feedback in order to correct the most critical diagnosis.

\section{Basic Structure of an Intelligent Tutoring System}

Intelligent Tutoring System (ITS) which is an educational software with artificial Intelligence component. Intelligent Systems are aligned with the goals and formative assessments to enhance effective learning process. The four main components of intelligent systems - Domain, Tutor, student and Interface models.

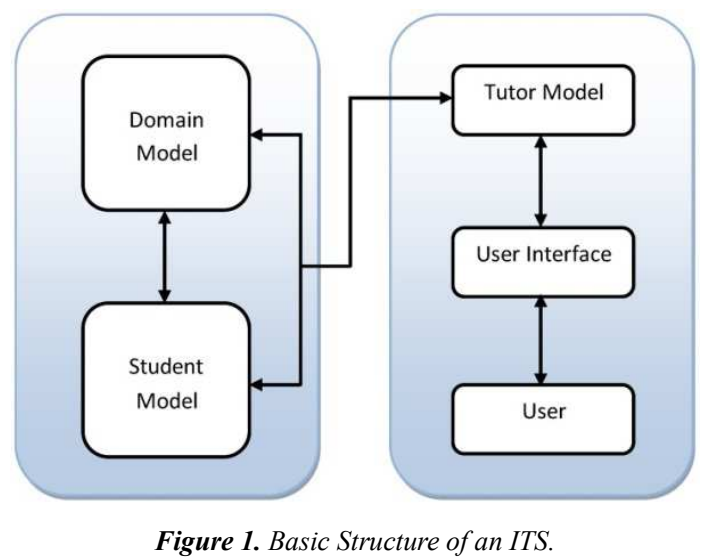

\subsection{Domain Model (The Expert Model)}

The domain model which is also referred to as the expert model consist of the knowledge of the domain expert that will help in delivering the expert flow [12]. Artificial Intelligence is used in almost all ITS domain expert module powering. This is because ITS powered by AI has shown more reliable than otherwise. Decision- making facilitation takes place here in the domain model.

\subsection{The Tutor Model}

This is responsible for the coordination of the works going on in the system by taking corrective checks on the learner's action and the expected actions from the domain expert knowledge. A mismatch signaled, causes the tutor model to take responsibility of correcting it or give suggestions to remedy the mismatch. This is to say that this module has in details the techniques for tutoring/learning stored in the student module. Recommendations are made here based on the student's attributes.

\subsection{The Student Model}

For every new student/learner, there is an account profiling data him/her. The students learning from the ITS is mainly by 
the process of solving problems, talking about problems that have been selected in the most appropriate manner. This serves as a learning process for the ITS.

\subsection{User Interface Model}

The User Interface Model offers the interactions between the students and the ITS enabled by the Graphic User Interface. GUI [13]. This module is otherwise called the communicating module. Some of them also implement a rich stimulation of tasks that the student is trying to learn. The User Interface Module needs three types of details for the dialogue implementation and this includes:

A detailed information about the model that generated the exact information that is required for maximum comprehension.

A detailed information about the necessary area for communication generation, and

Also, details about the necessary content for achieving the communication goal $[14,15]$.

The knowledge of the student is being assessed and the information is being updated as learning proceeds, all information maintained in the student module. The expected knowledge of the student which is domicile in the domainexpert model is then compared with it.

The fraction of the content which may be instructive or in assessment form is to be presented next taking into consideration the format to which it should be presented by the tutor model. The system then selects or generates a problem, try to provide an appropriate solution with the domain-expert from all of the considerations presented or it retrieves an already present solution.

Feedback is offered by the system based on considerations such as how long it has been since feedback was last provided, whether the student already received some particular advice, and so on. After this, the program updates the student model, and the entire cycle is repeated, starting with selecting or generating a new problem.

\section{Impacts of Intelligent Tutoring System on Learning}

A careful review carried out on previous researches has it prove that Intelligent Tutoring Systems are making a lot o positive and high impact on the learning approach. This has brought some visible contributions in enhancing learning thereby maximizing time.

The dynamism and flexibility of ITS has led to its massive adoption in all endeavors of learning.

It help learners acquire appropriate skills to perform highly independent tasks.

The use of Intelligent Tutoring System has the tendency of keeping learners engaged for a long duration thereby encouraging learning at one's pace. It's interactive nature, thereby enabling better exploration of potentials.

Increase in both quality and quantity, maximized performance, and high level productivity are some of the major impacts of ITS.

\section{Conclusion}

It can be concluded that the resultant positive effect of Intelligent Tutoring System on learning cannot be denied. Intelligent Tutoring System (ITS) are the earliest application of Artificial Intelligence learning. ITS employs the techniques from Artificial Intelligence in providing feedback that help learning.

It is very obvious that the traditional way of learning is become obsolete, hence the deployment of a simulating environment for impacting knowledge and skills. This research is important because it gives an overview of ITS and general impact on learning.

\section{References}

[1] Gordon, J. Using Business strategy to direct leadership development. Wiley Press. 2002.

[2] Banker, R. D., Field, J. M., Schroeder, R. G., \& Sinha, K. K. Impact of work teams on manufacturing performance: A longitudinal field study. Academy of Management Journal.1996; 39 (4), 867-890.

[3] Robbins, S. B., Lauver, K., Le, H., Davis, D., Langley, R., \& Calstron, A. Do Psychosocial and Study Skill Factors predict Colledge Outcomes? A Meta - Analysis.American Psychological Association. 2004; 130 (2), 261-288.

[4] Al-Bastami, B. G. H. \& Abu-Naser, S. S.A. Design and Development of an Intelligent Tutoring Sytem for C\# Language. European Academic Research. 2017; iv (10).

[5] Almurshdi, S. H. \& Naser, S. S. A. Design and Development of Diabetes IntelligentTutoring system. European academic Research. 2016; iv (9).

[6] Al-Dahdoo, R. \& Abu- Naser, S. S. Development and Evaluation of the Oracle Intelligent Tutoring System (OITS). European Academic Research. 2017; 4 (10), 8711-8721.

[7] Albatish, I., Mosa, M. J., \& Naser S. A. S. An Intelligent Training System on ARDUINO. International Journal of Engineering and Information Systems. 2018; 2 (1), 236-245.

[8] de Kok, I., Hulsmann, F., Waltemate, T.,\& Frank, C.The Intelligent Coaching Space: A Demonstration. Paper presented at the $17^{\text {th }}$ Conference IVA Stockholm Sweden.2017; 105-108.

[9] Anderson, K., André, E., Baur, T., Bernardini, S., Chollet, M., Chryssafidou, E., Sabouret, N. The TARDIS Framework: Intelligent Virtual Agents for Social Coaching in Job Interviews. 2013.

[10] Crowder, R. M., Robinson, M. A., Hughes, H., \& Sim, Y. The development of an agent based framework for simulating engineering teamwork. 2012.

[11] Duo, S., \& Ying Z.C. Personalized E- Learning System Based on Intelligent Agent. International Conferences on Applied Physics and Industrial Engineering. Physics Procedia 2012; 24, 1899-1902.

[12] Nkambou, R., Frasson, C., \& Gauthier, G. A New Approach to ITS-Curriculum and Course Authoring: The Authoring Environment. Computers \& Education, 1998; 31, 105-130. 
Chidi Ukamaka Betrand et al.: Overview of Intelligent Tutoring System in Human Teamwork and Its Impact Generally on Learning

[13] Salgueiro, F., Costa, G., Cataldi, Z., Lage, F., \& Garcia, R. Redefinition of Basic Modules of an Intelligent Tutoring System: The Tutor Module Workshop ITS's on the 8th World Conference of the AIED Society, Kobe, Japan, 18-22,August 2005, 18-22.

[14] Frasson, C., \& Aimeur, E. Designing a Multi-Strategic
Intelligent Tutoring System for Training in Industry. Computers in Industry. 1998; 37, 153-167.

[15] Self, J. A. The Distinctive Characteristics of Intelligent Tutoring Systems Research: ITSs Care, Precisely. International Journal of Artificial Intelligence in Educa tions.1999; 10, 350-364. 